Artikel Review

\title{
Anemia Ibu Hamil dan Efeknya pada Bayi
}

\author{
Kamilia Farhan*, Devieka Rhama Dhanny \\ Program Studi Gizi, Fakultas Ilmu-Ilmu Kesehatan, Universitas Muhammadiyah Prof. Dr. HAMKA, Indonesia \\ *Corresponding author: kamiliafarhan@gmail.com
}

\begin{abstract}
Background: The incidence of anemia is increasing from year to year. The LBW (low birth weight) prevalence of infants is also escalating. Anemia can be the cause of another health problems besides LBW (low birth weight). Method: Literature study for 10 english articles that published from 2015-2020 in database PubMed, Google Scholar, and Wiley Online Library. The articles are searched with keywords that picked from the title of this study. Results: There are 10 articles filtered from exclusion and inclusion criteria. From this study, we found out that there are some factors that can be the trigger of $L B W$, the risks of all different stage of anemia, and the risks of different gestation age of diagnosis. Conclusion: Effects that can happen on neonatal and infants health problems from anemia-diagnosed mother are LBW (low birth weight), abortus, premature birth, and ASD (autistic spectrum disorder).
\end{abstract}

Keywords: anemia, infant, the effects of anemia, pregnancy

\begin{abstract}
ABSTRAK
Latar Belakang: Kejadian anemia pada ibu hamil semakin meningkat tiap tahunnya. Angka kejadian BBLR (berat badan lahir rendah) pada bayi pun ikut meningkat. Anemia dapat menjadi penyebab timbulnya masalah lainnya selain BBLR. Metode: Studi literatur pada 10 jurnal berbahasa inggris dengan rentang tahun terbit 2015-2020 dari database PubMed, Google Scholar, dan Wiley Online Library. Pencarian jurnal dilakukan melalui kata kunci yang berasal dari judul penelitian ini. Hasil: Studi literatur ini didapat dari 10 artikel yang diseleksi dari kriteria inklusi dan eksklusi. Dari hasil kajian artikel, diketahui beberapa faktor terjadinya BBLR, perbedaan tingkatan anemia dan risikonya, dan perbedaan usia kehamilan saat diagnosa anemia dan risikonya. Kesimpulan: Efek yang terjadi pada bayi yang lahir dari ibu hamil yang menderita anemia diantaranya BBLR (berat badan lahir rendah), abortus kandungan, usia lahir rendah atau prematur, dan ASD (autistic spectrum disorder).
\end{abstract}

Kata kunci: anemia, bayi, efek anemia, kehamilan

\section{PENDAHULUAN}

Kualitas sumber daya manusia yang baik menjadi elemen pendukung majunya Negara Kesatuan Republik Indonesia (NKRI) di era globalisasi ini. Untuk mendapatkan kualitas SDM yang baik, seorang calon ibu harus mencukupi asupan gizinya sehingga janin dapat tumbuh sehat dan lahir dalam keadaan normal. Interaksi lingkungan yang baik diperlukan untuk perkembangan anak yang optimal (1). 
Kondisi terjadinya penurunan jumlah sel darah merah untuk memenuhi kebutuhan fisiologis tubuh disebut anemia. Beberapa faktor penyebab bervariasinya kebutuhan fisiologis spesifik pada manusia diantaranya usia, jenis kelamin, kebiasaan merokok, dan tahap kehamilan (2).

Anemia terdiri dari anemia defisiensi besi, anemia defisiensi vitamin (vitamin B12 \& B9), anemia peradangan (kanker, HIV/AIDS, rheumatoid arthritis, penyakit ginjal, penyakit Crohn's), anemia aplastik (pembentukan darah terganggu), anemia yang berkaitan dengan penyakit tulang sumsum (leukemia dan myelofibrosis), anemia hemolitik (sel darah merah lebih cepat hancur), dan anemia sel sabit (sel darah merah berbentuk sabit dan lebih cepat mati) (3). Tiap jenis anemia memiliki defisiensi zat gizinya masing-masing, dan tiap defisiensi memiliki efeknya masingmasing pada janin maupun bayi.

Anemia yang umum terjadi saat kehamilan yakni anemia defisiensi besi (3). Zat besi (Fe) pada masa kehamilan akan digunakan sebagai salah satu zat pembentuk plasenta dan sel darah merah. Terdapat peningkatan kebutuhan Fe pada ibu hamil yakni sebesar 200-300\% atau dengan perkiraan berat sebesar $1040 \mathrm{mg}$. Secara detail, distribusi zat besi dalam tubuh ibu hamil yakni diantaranya penyaluran ke janin sebesar $300 \mathrm{mg}$, perkembangan plasenta sebesar 50-75 mg, menjaga jumlah sel darah merah sebesar $450 \mathrm{mg}$, serta digunakan saat melahirkan sebesar $200 \mathrm{mg}$ (4).

Persentase munculnya anemia gestasional skala nasional sendiri pada hasil riset kesehatan dasar terakhir yaitu 48,9\%. Angka ini merupakan peningkatan dari prevalensi tahun sebelumnya yakni 37,1. Sementara itu, dari klasifikasi umur, diketahui bahwa wanita berumur 15-24 tahun memiliki prevalensi tertinggi diantara umur lain di atasnya yaitu 84,6\% (5).
Angka ini lebih tinggi dengan prevalensi wanita hamil anemia berumur 15-49 tahun di dunia yakni $38 \%$ (2). Hal ini menunjukkan adanya pengetahuan yang kurang dari ibu usia muda mengenai pentingnya kecukupan gizi saat hamil.

Terdapat beberapa penyakit atau kelainan pada bayi sebagai akibat dari tiap jenis defisiensi anemia pada ibu hamil. Pada kondisi kekurangan B12 misalnya, dapat berakibat pada kecacatan tabung saraf/neural tube defect (6). Kecacatan tabung saraf terjadi ketika tabung saraf tidak menutup dengan sempurna. Tabung saraf membentuk otak dan saraf tulang belakang. Kelainan ini dimulai pada tahap awal kandungan, bahkan ketika ibu belum menyadari kehamilannya (7). Selain itu, salah satu tipe kecacatan tabung saraf bernama spina bifida juga dapat ditemukan pada ibu defisiensi folat (6). Spina bifida merupakan kondisi ketika tulang belakang dan sarafnya tidak terbentuk secara sempurna akibat tabung saraf yang tidak tertutup sempurna. Beberapa komplikasi dari spina bifida sendiri diantaranya yakni gangguan bergerak dan berjalan, komplikasi ortopedik, dan gangguan-gangguan otak (8).

Melalui hasil observasi diatas, penulis tertarik untuk melakukan penelitian mengenai dampak anemia yang terjadi pada ibu hamil sehingga nantinya dapat terlihat secara jelas pentingnya mencegah anemia untuk memenuhi perkembangan dan pertumbuhan bayi juga janin.

\section{TINJAUAN LITERATUR}

Kualitas kesehatan ibu selama kehamilan adalah faktor penting pertumbuhan janin yang optimal. Oleh sebab itu, asupan zat gizi di masa ini sangat krusial karena selain mencukupi kebutuhan ibu, tubuh juga akan berusaha mencukupi kebutuhan janin yang tumbuh di dalamya. Salah satu tanda tidak tercukupinya kebutuhan ibu selama 
kehamilan adalah terjadinya anemia. Dengan mengkaji 10 artikel terkait yang diterbitkan pada situs jurnal resmi berbahasa Inggris dalam rentang tahun 2015-2020, berikut beberapa masalah yang dapat terjadi pada bayi jika ibu menderita anemia selama masa kehamilan.

\section{a. Berat Badan Lahir Rendah (BBLR)}

Berat Badan Lahir Rendah (BBLR) adalah kondisi bayi yang lahir dengan berat badan kurang dari 2500 gram. Bayi BBLR memiliki tingkat kerentanan penyakit dan kegagalan organ vital yang tinggi saat lahir (9). Pada tahun 2018, diketahui bahwa ratarata jumlah bayi BBLR di Indonesia mencapai 6,2\%. Angka ini telah memenuhi target RPJMN 2019 yakni 8\% (10). Namun begitu, dengan selisih angka yang kecil, peningkatan dapat terjadi dengan mudah di tahun-tahun selanjutnya, sehingga masalah BBLR perlu tetap diperhatikan. Beberapa faktor terjadinya BBLR diantaranya umur kehamilan, kehamilan ganda, hipertensi, dan anemia saat hamil (11). Pada penelitian kohort yang dilaksanakan selama 10 bulan di Pakistan, diketahui bahwa ibu yang anemia memiliki risiko kelahiran bayi BBLR 2,4 kali lebih besar daripada ibu yang tidak terkena anemia (12).

Tabel 1. Risiko bayi BBLR pada ibu hamil

\begin{tabular}{lccccc}
\hline Variabel & $\begin{array}{c}\text { Anemia } \\
(\mathbf{n = 3 4 2})\end{array}$ & $\begin{array}{c}\text { Non- } \\
\text { anemia }\end{array}$ & $\begin{array}{c}\text { RR } \\
\text { (n) }\end{array}$ & $\begin{array}{c}\mathbf{9 5 \%} \\
\text { CI }\end{array}$ & $\begin{array}{c}\text { P } \\
\text { value }^{* * *}\end{array}$ \\
\hline \multicolumn{6}{l}{ Berat badan lahir rendah (BBLR) } \\
Ya & 124 & 44 & & & \\
\multirow{4}{*}{ Tidak } & $(36,3 \%)$ & $(14,6 \%)$ & 2.48 & $1.8-$ & $<0,001$ \\
& 218 & 257 & & $3.3 \%$ & \\
\hline
\end{tabular}

Sumber: Anwar, dkk (2019)

*RR: Risiko relative

**chi-square test p-value

Selain itu, jika anemia dibagi menjadi tiga kategori yakni ringan $(<7.0 \mathrm{~g} / \mathrm{dl})$, sedang (8.9-7.0g/dl), dan berat (10.9- 9.0g/dl), ibu dengan anemia berat lebih tinggi risikonya melahirkan bayi BBLR dibanding ibu dengan anemia sedang (13). Semakin tinggi keparahan anemia pada ibu hamil, semakin tinggi risiko bayi lahir dengan kondisi BBLR (14).

Seiring bertambahnya usia kehamilan, kebutuhan gizi ibu juga terus bertambah. Pada trimester kedua dan ketiga, terdapat penambahan kebutuhan zat besi sebesar $9 \mathrm{mg}$, sedangkan di trimester pertama tidak ada penambahan karena pertumbuhan janin masih lambat (15). Pada trimester kedua dan ketiga, ibu hamil akan mengalami pertambahan $35 \%$ dari volume darah yang setara dengan $450 \mathrm{mg}$ zat besi untuk membuat sel darah merah baru. Pertambahan sel darah ini akan digunakan untuk pemenuhan kebutuhan oksigen dan zat gizi janin hingga dilahirkan. Semakin rendah pertambahan sel darah, maka semakin sedikit zat gizi yang diterima janin untuk pertumbuhan dan perkembangannya (16).

Ibu dengan anemia pada trimester kedua lebih berisiko pada bayi BBLR daripada ibu yang tidak anemia (17). Namun pada penelitian lain, risiko bayi BBLR lebih rendah pada ibu yang terkena anemia di trimester ketiga dibanding yang tidak anemia (18). Selain itu, bayi perempuan yang lahir dari ibu anemia memiliki berat lahir yang lebih besar dari ibu yang tidak anemia (19).

\section{b. IUGR (Intrauterine Growth Restriction)}

IUGR adalah kondisi janin yang tidak berkembang secara sempurna yang disebabkan oleh faktor genetik ataupun lingkungan. Penyebab umum dari IUGR adalah malfungsi kronis pada plasenta yang mengganggu pemasokan oksigen dan zat gizi ke janin sehingga menyebabkan perkembangan janin tidak normal. Bayi 
dengan IUGR memiliki berat badan kurang dari persentil ke-10 untuk usia kehamilannya, bahkan semakin menurun melewati persentil pertumbuhan dari waktu ke waktu (20). Risiko lahirnya bayi dengan IUGR 2,8 kali lebih besar pada ibu yang terkena anemia daripada ibu yang tidak terkena anemia (12).

Tabel 2. Risiko Bayi IUGR pada Ibu Hamil

\begin{tabular}{lccccc}
\hline Variabel & $\begin{array}{c}\text { Anemia } \\
(\mathbf{n = 3 4 2})\end{array}$ & $\begin{array}{c}\text { Non- } \\
\text { anemia }\end{array}$ & $\begin{array}{c}\text { RR } \\
*\end{array}$ & $\begin{array}{c}\mathbf{9 5 \%} \\
\text { CI }\end{array}$ & $\begin{array}{c}\text { P } \\
\text { value }^{* *}\end{array}$ \\
\hline IUGR & & & & & \\
Ya & 42 & 13 & & & \\
& $(12,2 \%)$ & $(4,3 \%)$ & 2.84 & $1.55-$ & $<0,001$ \\
Tidak & 300 & 288 & & 5.1 & \\
& $(87,7 \%)$ & $(95,7 \%)$ & & & \\
\hline
\end{tabular}

Sumber: Anwar, dkk (2019)

*RR: Risiko relative

**chi-square test p-value

Kelainan lain yang dapat ditimbulkan oleh IUGR adalah "brain-sparing". Brainsparing adalah kondisi dimana ukuran tubuh dan kepala bayi tidak proporsional, yakni kepala bayi lebih besar dari ukuran tubuhnya. Hal ini terjadi karena hipoksia (kurangnya pasokan oksigen) kronis yang terjadi pada bayi IUGR mengakibatkan darah sebagian besar dialirkan ke otak. Otak mendapatkan pasokan gizi dan oksigen yang terbanyak dari organ lainnya, sehingga pertumbuhan dan perkembangan otak menjadi yang paling dominan. Beberapa penelitian menunjukkan bahwa bayi IUGR disertai brain-sparing memiliki kondisi perkembangan saraf otak yang lebih buruk dari bayi IUGR tanpa brainsparing (20).

\section{c. Kelahiran Prematur}

Kelahiran prematur adalah bayi yang lahir sebelum umurnya mencapai 37 minggu di dalam kandungan ibu (21). Bayi yang lahir dari ibu anemia memiliki risiko 4,5 kali lebih tinggi lahir secara prematur dari ibu yang tidak anemia (12).
Tabel 3. Risiko Bayi Lahir Prematur pada Ibu

\begin{tabular}{lccccc}
\multicolumn{6}{c}{ Hamil } \\
\hline Variabel & $\begin{array}{c}\text { Anemia } \\
(\mathbf{n = 3 4 2})\end{array}$ & $\begin{array}{c}\text { Non- } \\
\text { anemia }\end{array}$ & RR$^{*}$ & $\begin{array}{c}\mathbf{9 5 \%} \\
\mathbf{C I}\end{array}$ & $\begin{array}{c}\mathbf{P} \\
\text { value }\end{array}$ \\
\hline \multicolumn{4}{l}{ Bayi lahir } \\
Ya & 229 & 44 & & & \\
& $(66,9 \%)$ & $(14,6 \%)$ & 4.5 & $3.4-$ & $<0,001$ \\
Tidak & 113 & 257 & & 6.0 & \\
& $(33 \%)$ & $(85,3 \%)$ & & & \\
\hline
\end{tabular}

Sumber: Anwar, dkk (2019)

$*$ RR: Risiko relative

**chi-square test $p$-value

Selain itu, jika dihubungkan dengan tingkat keparahan anemia, ibu dengan anemia berat memiliki kemungkinan lebih tinggi melahirkan di usia prematur dibanding ibu yang memiliki anemia sedang (13). Ibu yang mengalami anemia di trimester kedua dan ketiga juga lebih tinggi mengalami kelahiran prematur dibanding ibu yang tidak anemia $(17,18)$.

\section{d. Kematian Janin}

Kematian janin adalah kondisi gugurnya janin secara spontan dalam kandungan (22). Ibu dengan anemia memiliki risiko bayi lahir mati lebih tinggi dari ibu yang tidak anemia. Risiko ini juga meningkat jika ibu memiliki status gizi kurang (IMT <18 $\mathrm{kg} / \mathrm{m}^{2}$ ) (23). Selain itu, ibu dengan anemia berat memiliki kemungkinan bayi lahir mati lebih tinggi dari ibu yang terkena anemia sedang ataupun yang tidak anemia (13). Jika dihubungkan dengan usia kehamilan, janin lebih rentan mengalami kematian pada ibu yang mengalami anemia di trimester 2 dan $3(17,18)$.

\section{e. Kematian Bayi Pasca Kelahiran}

Kematian bayi pasca lahir (neonatal death) adalah keadaan dimana bayi bertahan hidup hanya dalam waktu kurang dari 28 hari setelah dilahirkan (kematian neonatal). 
Kasus kematian bayi baru lahir ditentukan oleh derajat keparahan anemia yang diderita oleh ibu hamil. Semakin tinggi tingkat keparahannya, maka semakin besar risiko kematian bayi baru lahir <28 hari (24). Risiko ini juga meningkat jika ibu memiliki status gizi kurang (IMT <18 $\mathrm{kg} / \mathrm{m}^{2}$ ) (23). Secara spesifik, jika ibu terkena anemia di trimester pertama, maka risiko ini lebih tinggi dibanding ibu yang anemia di trimester ketiga (12).

\section{SIMPULAN}

Berdasarkan hasil telaah artikel yang telah dilakukan, diketahui bahwa efek-efek yang dapat terjadi pada bayi akibat ibu yang menderita anemia selama kehamilan diantaranya BBLR (berat badan lahir rendah), IUGR (Intrauterine Growth Restriction), abortus kandungan, usia lahir rendah atau prematur serta kematian bayi pasca kelahiran. Dari hasil penelitian ini, sebaiknya ibu hamil harus memastikan tercukupinya asupan selama hamil terutama zat besi. Selain itu, saran ini juga berlaku untuk para wanita dewasa maupun muda untuk mencegah terjadinya kasus-kasus diatas sejak dini.

\section{UCAPAN TERIMA KASIH}

Penulis haturkan terima kasih kepada berbagai pihak yang telah mendukung penelitian ini, terutama orangtua sebagai penyedia fasilitas akademik penulis serta dosen yang telah memberi saran dan kritik terkait penelitian.

\section{KONFLIK KEPENTINGAN}

Tidak terdapat konflik kepentingan maupun afiliasi atau koneksi jenis apapun dari penulis yang dapat menimbulkan bias pada keseluruhan artikel ini.

\section{REFERENSI}

1. Warsini KT, Hadi H, Nurdiati DS.
Riwayat KEK dan anemia pada ibu hamil tidak berhubungan dengan kejadian stunting pada anak usia 623 bulan di Kecamatan Sedayu, Bantul, Yogyakarta CED and maternal anemia did not associate with stunting in children 6-23 months in Sedayu Subdistrict, Bantu. J Gizi dan Diet Indones. 2016;4(1):29-40.

2. World Health Organization. Anemia [Internet]. 2020. Available from: https://www.who.int/healthtopics/anaemia\#tab=tab_1

3. Mayo Clinic. Anemia [Internet]. 2019. p. 1. Available from: https://www.mayoclinic.org/disease s-conditions/anemia/symptomscauses/syc-20351360

4. Hariati, Alim A, Thamrin AI. Kejadian Anemia Pada Ibu Hamil (Studi Analitik di Puskesmas Pertiwi Kota Makassar Provinsi Sulawesi Selatan). J Ilm Kesehat. 2019;1(1):8-17.

5. Kementerian Kesehatan. Hasil Utama Riskesdas 2018 [Internet]. 2018. p. 5-200. Available from: https://kesmas.kemkes.go.id/assets/ upload/dir_519d41d8cd98f00/files/ Hasil-riskesdas-2018_1274.pdf

6. Laguipo ABB. Dangers of Vitamin Deficiency During Pregnancy [Internet]. 2019. p. 1-8. Available from: https://www.newsmedical.net/health/Dangers-ofVitamin-Deficiency-DuringPregnancy.aspx\#6

7. Centers for Disease Control and Prevention. Facts About Neural Tube Defect [Internet]. 2020. Available from: https://www.cdc.gov/ncbddd/birthd efects/facts-about-neural-tube- 
defects.html

8. Mayo Clinic. Spina bifida [Internet]. 2021. Available from: https://www.mayoclinic.org/disease s-conditions/spina-

bifida/symptoms-causes/syc20377860

9. Sukirno RSH. Kesabaran Ibu Merawat Bayi Berat Lahir Rendah (BBLR). J Psychol Perspect. 2019;1(1):1-13.

10. Kementerian Kesehatan Republik Indonesia. Hasil Utama RISKESDAS 2018. Jakarta: Balitbangkes KEMENKES RI; 2018.

11. Purwanto AD, Wahyuni CU. Hubungan Antara Umur Kehamilan, Kehamilan Ganda, Hipertensi dan Anemia dengan Kejadian Bayi Berat Lahir Rendah (BBLR). J Berk Epidemiol. 2016;4(3):349-59.

12. Anwar R, Razzaq K, Noor N. Impact of Maternal Anemia and Perinatal Outcomes. Pakistan Armed Forces Med J. 2019;69(2):397-402.

13. Nair M, Choudury MK, Choudury SS, Kakoty SD, Sarma UC, Webster $\mathrm{P}$, et al. Association between Maternal Anemia and Pregnancy Outcomes: Cohort Study in Assam, India. Br Med J. 2016;1(1):1-9.

14. Al-Hajjiah NN, Almkhadree MA. The Effect of Maternal Anemia on Anthropometric Measurements in Full-term Neonates. Asian J Phermaceutical Med Res. 2018;11(4):422-4.

15. Fitriah AH, Supariasa IDN, Riadi BD, Bakri B. Buku Praktis Gizi Ibu Hamil. Malang: Media Nusa Creative; 2018.

16. Susiloningtyas I. Pemberian Zat Besi (Fe) dalam Kehamilan. In: Majalah
Ilmiah Sultan Agung. 50th ed. Semarang: Universitas Islam Sultan Agung; 2012. p. 1-27.

17. Vural T, Toz E, Özcan A, Biler A, İleri A, İnan AH. Can anemia predict perinatal outcomes in different stages of pregnancy? Pakistan J Med Sci [Internet]. 2016 Nov 15;32(6). Available from: http://pjms.com.pk/index.php/pjms/ article/view/11199

18. Fatemeh; H, Soltani M, Najafi F, Tabatabaee HR, Etemad K, Hajipour $\mathrm{M}$, et al. Maternal Anemia in Various Trimesters and Related Pregnancy Outcomes: Result From a Large Cohort Study in Iran. Iran J Pediatr Hematol Oncol. 2019;29(1):e69741.

19. Orlandini C, Toricelli M, Spirito N, Alaimo L, Tommaso M Di, Severi FM, et al. Maternal Anemia Effects during Pregnancy on Female and Male Fetuses; Are There Any Differences? J Matern Neonatal Med. 2016;1704-8.

20. Wixey JA, Chand KK, Colditz PB, Bjorkman ST. Review: Neuroinflammation in intrauterine growth restriction. Placenta. 2017 Jun;54:117-24.

21. World Health Organization. Preterm Birth [Internet]. 2018. Available from: https://www.who.int/newsroom/fact-sheets/detail/preterm-

birth

22. National Vital Statistics System. Fetal Deaths [Internet]. 2020. Available from: https://www.cdc.gov/nchs/nvss/fetal _death.htm

23. Patel A, Prakash AA, Das PK, Gupta S, Pusdekar YV, Hobberd PL. Maternal Anemia and Underweight 
as Determinants of Pregnancy

Outcomes: Cohort Study in Eastern Rural Maharashtra, India. Br Med J. 2018;8(8):1-15.

24. Parks S, Houffman M, Patel A, Saleem S, Ali S, Goldenberg R, et al. Maternal Anaemia and Maternal, Fetal, and Neonatal Outcomes in a Prospective Cohort Study in India and Pakistan. Br J Obstet Gynaecol. 2018;126(6):737-43. 